\title{
Predictive values of maternal serum PAPP-A level, uterine artery Doppler velocimetry, and fetal biometric measurements for poor pregnancy and poor neonatal outcomes in pregnant women
}

\author{
Serdar Balcı \\ Department of Gynecology and Obstetrics, Başkent University School of Medicine, Ankara, Turkey
}

\begin{abstract}
Objective: To determine predictive values of maternal serum PAPP-A (msPAPP-A) levels, uterine artery Doppler velocimetry, and fetal biometric measurements (FBMs) for poor pregnancy and poor neonatal outcomes.

Material and Methods: This prospective cohort study was conducted on singleton pregnancies followed until delivery. Pregnancy and neonatal outcomes were evaluated with respect to the msPAPP-A level at the $11^{\text {th }}-14^{\text {th }}$ weeks, uterine artery Doppler velocimetry at the $15^{\text {th }}-18^{\text {th }}$ weeks, and FBMs at the $20^{\text {th }}-24^{\text {th }}$ and $28^{\text {th }}-32^{\text {nd }}$ weeks of pregnancy.

Results: One hundred fifty-eight women constituted the study group; 17 (10.75\%) of them had at least one poor pregnancy outcome. The cut-off point of 0.72 multiple of the median (MoM) for the PAPP-A level achieved a sensitivity of $82.4 \%$ and a specificity of $29.8 \%$ for poor pregnancy outcomes. The mean birth weight was significantly lower in the subgroup with a higher mean pulsatility index of uterine arteries (UAPImean $\geq 1.19$ ) $(p=0.025)$ as well as in the subgroup with a higher mean resistance index of uterine arteries (UARImean $\geq 0.62)(p=0.013)$. When the subgroup of pregnant women under the risk of early-onset IUGR according to FBMs was compared to the low-risk group, statistically significant differences were seen in terms of pregnancy outcomes $(p=0.045)$ and birth weight $(p=0.011)$.

Conclusion: Maternal serum PAPP-A level and FBMs could be used for predicting pregnancy outcomes, while uterine artery Doppler velocimetry and FBMs could be used for predicting neonatal outcomes, specifically the birth weight. (J Turk Ger Gynecol Assoc 2016; 17: 143-9)

Keywords: Pregnancy-associated plasma protein-a, ultrasonography, Doppler, color, fetal biometry, pregnancy outcome, fetal development

Received: 7 March, 2016 Accepted: 21 July, 2016
\end{abstract}

\section{Introduction}

Preeclampsia and intrauterine growth restriction (IUGR), as well as related perinatal death or preterm birth before the $32^{\text {nd }}$ week of pregnancy, are very closely related with the underlying potential placental pathology. In the last 25 years, many studies have been conducted regarding the early recognition of placental insufficiency. Doppler flow measurements of uterine and umbilical arteries, as well as maternal serum alpha fetoprotein (AFP) and human chorionic gonadotropin (hCG) levels, during the first and second trimesters of pregnancy are most frequently studied to predict placental insufficiency and its effects on the fetus (1).

Uterine artery Doppler velocimetry results have demonstrated that hemodynamic changes detectable in the uterine artery as early as in the first trimester of pregnancy are associated with an increased risk of preeclampsia and IUGR (2-4). This association can also be demonstrated in the second and third trimesters (5-7).
Several studies have recently shown that low serum levels of pregnancy-associated plasma protein A (PAPP-A) might be associated with poor pregnancy and poor neonatal outcomes $(1,8,9)$. PAPP-A, which was first purified from the serums of pregnant women in 1974, is a member of the metzincin family of metalloproteinases $(10,11)$. PAPP-A is an insulin-like growth factor-binding protein (IGFBP)-specifically, a protease. IGFBPs bind to insulin-like growth factor (IGF) 1 and 2 and disconnect these proteins from cell surface receptors; thus, low levels of serum PAPP-A are associated with low levels of bioactive IGF (11).

A low level of maternal serum PAPP-A is an important sign of early placental insufficiency in the first three months of pregnancy; however, the effects on the fetus reaches recognizable levels in the second trimester. Nevertheless, growth restriction determined in the second trimester is also directly associated with poor pregnancy and poor neonatal outcomes. Detailed ultrasonography for fetal biometric measurements (FBMs) and Doppler flow measurements that would be performed in the second trimester in patients with low levels of serum PAPP-A, 
which is measured routinely within the scope of first-trimester aneuploidy screening at the $11^{\text {th }}-14^{\text {th }}$ weeks of pregnancy may be beneficial in predicting poor pregnancy and poor neonatal outcomes and in taking necessary measures $(12,13)$.

The present study aimed to determine the predictive value of maternal serum PAPP-A levels measured in the first trimester, uterine artery Doppler velocimetry performed during the second trimester, and FBMs in the second and third trimesters for poor pregnancy and poor neonatal outcomes in pregnant women.

\section{Material and Methods}

This prospective cohort study was conducted in a single university-based pregnancy clinic in the Department of Gynecology and Obstetrics in Turkey between July 2013 and July 2015, with approval of the hospital ethics committee. The singleton pregnant women, who presented to our pregnancy clinic, were enrolled into the study from September 2013 to May 2015 after their informed consents were obtained. The study complied with the Declaration of Helsinki and ethical standards. Pregnant women were excluded from the final analyses if they missed follow-up visits or had complicated pregnancies, such as abortion or iatrogenic termination of the pregnancy.

The women included in the study were followed up after the confirmation of pregnancy until delivery. Initially, all the study participants underwent the first-trimester aneuploidy screening test at the $11^{\text {th }}-14^{\text {th }}$ weeks of pregnancy, including maternal serum PAPP-A, $\beta$-hCG, and nuchal translucency measurements. Subsequently, color pulsed Doppler ultrasound examination of the bilateral uterine arteries was performed at the $15^{\text {th }}-18^{\text {th }}$ weeks of pregnancy. The women with diastolic notches, unilateral or bilateral, in the uterine artery Doppler waveforms were recorded. The pulsatility index (PI) and resistance index (RI) of both uterine arteries were measured and their arithmetic means were calculated. FBMs, including fetal biparietal diameter (BPD), head circumference (HC), femur length (FL), and abdominal circumference (AC), were measured at the $20^{\text {th }}-24^{\text {th }}$ and $28^{\text {th }}-32^{\text {nd }}$ weeks of pregnancy, and the $\mathrm{HC} / \mathrm{AC}$ ratio was calculated. Poor pregnancy outcomes, such as pregnancy-induced hypertension, preeclampsia, and preterm birth, and poor neonatal outcomes as well as birthweight measured at delivery were noted. Women were divided into two groups according to the pregnancy or neonatal outcomes: the group with and the group without poor outcomes. These two groups were compared with each other with respect to the test results specified above, in order to determine the predictive values of the analyses.

All the clinic-demographic characteristics and test results were recorded in a prospectively formed electronic database. All the ultrasonographic measurements were performed by the same physician, using color Doppler ultrasound (Voluson 730 Expert, General Electric Healthcare; Chicago, USA) and the data were assessed by a single researcher.

Pregnant women were considered to be under risk of early-onset IUGR when the estimated gestational age according to the ultrasonographic FBMs at the $20^{\text {th }}-24^{\text {th }}$ and $28^{\text {th }}-32^{\text {nd }}$ weeks of pregnancy was more than one-week behind the gestational age calculated according to the last menstrual period (LMP) and when $\mathrm{HC} / \mathrm{AC}$ ratio was over 1.15 and 1.10 at the $20^{\text {th }}-24^{\text {th }}$ and $28^{\text {th }}-32^{\text {nd }}$ weeks of pregnancy, respectively $(12,13)$. This group was compared with the group of pregnant women in whom the estimated gestational age according to the FBMs was consistent with the gestational age calculated according to the LMP, with respect to the test results as well as pregnancy outcomes, including the birth weight.

Pregnancy-induced hypertension (PIH) was diagnosed if the arterial blood pressure of the patient was $140 / 90 \mathrm{mmHg}$ and higher, whereas the diagnosis of preeclampsia was made if a high blood pressure was accompanied by proteinuria $\geq 300 \mathrm{mg}$ in 24 hours (14). Birth before the $37^{\text {th }}$ week of pregnancy was considered as a preterm birth. The threat of preterm labor was diagnosed when there were regular uterine contractions (4 per 20 minutes) without any cervical dilatation before the $37^{\text {th }}$ week of pregnancy. Preterm premature rupture of the membranes (PPROM) was defined as rupture of the membranes before the onset of labor before the $37^{\text {th }}$ week of pregnancy. Low birth weight was defined as a birth weight $<2500 \mathrm{~g}$.

A prospective cohort study design was chosen to conduct the study in order to minimize a potential bias that could result from the nature of the trial. In addition, ultrasonographic measurements and the data assessment were performed by two different researchers.

Data were analyzed by Chi-square, Mann-Whitney U test, and Student t-test using SPSS (Statistical Package for Social Sciences version 15.0, SPSS Inc.; Chicago, USA) program. A value of $\mathrm{p}<0.05$ was considered as statistically significant. The parameters assumed to predict pregnancy outcomes were evaluated by receiver operating characteristic (ROC) curves.

\section{Results}

A total of 175 singleton pregnant women were enrolled in the study. Of these pregnancies, three were terminated due to missed abortion and one was terminated due to Trisomy 21 . Thirteen patients were lost to follow-up at different phases of the study. The remaining 158 patients formed the study group. Table 1 summarizes the clinicodemographic characteristics of the study participants. Over the course of the follow-up period, a total of $17(10.75 \%)$ pregnant women were determined to have at least one of the poor pregnancy outcomes (Table 2).

An ROC curve generated for the first-trimester maternal serum PAPP-A values is presented in Figure 1. Considering the cut-off value as a 0.72 multiple of the median (MoM), (Standard Error, SE: 0.039) (95\% CI 0.646-0.798), the sensitivity, specificity, positive predictive value (PPV), and negative predictive value (NPV) achieved for the poor pregnancy outcomes were $82.4 \%, 29.8 \%$, $67 \%$, and $56 \%$, respectively.

In the ROC curve analysis of the arithmetic mean of PI of the right and left uterine arteries (UAPImean), the cut-off value was considered to be 1.08 with $58.8 \%$ sensitivity, $48.2 \%$ specificity, $76 \%$ PPV, and 55\% NPV for poor pregnancy outcomes (Standard Error, SE: 0.039) (95\% CI 0.646-0.798) (Figure 2). Pregnancy outcomes were compared between the two groups formed based 
Table 1. Clinicodemographic characteristics of the study participants $(n=158)$

\begin{tabular}{|l|c|c|}
\hline Characteristics & $\begin{array}{c}\text { Descriptive values } \\
\text { (mean } \pm \text { SD or n) }\end{array}$ & $\begin{array}{c}\text { Additional } \\
\text { explanation }\end{array}$ \\
\hline Age & $27.9 \pm 4.4$ years & Range: $17-41$ \\
\hline Weight & $62.8 \pm 10.1 \mathrm{~kg}$ & Range: $42-108$ \\
\hline Smoking & 8 women (5.06\%) & $2-8$ cigarettes day \\
\hline First pregnancy & 64 women (40.5\%) & - \\
\hline $\begin{array}{l}\text { Previous poor pregnancy } \\
\text { outcome }\end{array}$ & 18 women (11.4\%) & $\begin{array}{c}\text { PIH, Preeclampsia, GDM, } \\
\text { Preterm birth, PPROM, } \\
\text { IUGR, Trisomy 21, } \\
\text { Fetal anomaly }\end{array}$ \\
\hline Concomitant disease & 13 women (8.2\%) & $\begin{array}{c}\text { Hypo-hyperthyroidism, } \\
\text { FMF, Psoriasis, Cardiac } \\
\text { valve diseases, Chronic } \\
\text { HT, } \\
\text { Asthma, Thalassemia } \\
\text { carrier }\end{array}$ \\
\hline Medications & 7 women (4.4\%) & $\begin{array}{c}\text { Levothyroxine, } \\
\text { Colchicine, } \\
\text { Alfa methyldopa }\end{array}$ \\
\hline
\end{tabular}

PIH: pregnancy-induced hypertension; GDM: gestational diabetes mellitus; PPROM: preterm premature rupture of the membranes; IUGR: intrauterine growth restriction; FMF: familial Mediterranean fever; HT: hypertension

Table 2. Numeric and proportional distribution of poor pregnancy outcomes determined during follow-up

\begin{tabular}{|l|c|c|}
\hline Outcomes & $\begin{array}{c}\text { Number of patients } \\
(\mathbf{n}=\mathbf{1 7})\end{array}$ & $\begin{array}{c}\text { Percentage (\%) } \\
(\mathbf{n}=158)\end{array}$ \\
\hline PIH/Preeclampsia & $5(3 / 2)$ & 3.16 \\
\hline Threat of preterm labor & 1 & 0.63 \\
\hline PPROM & 4 & 2.53 \\
\hline Preterm birth $<37^{\text {th }}$ week & 14 & 8.86 \\
\hline Preterm birth $<32^{\text {nd }}$ week & - & - \\
\hline Need for neonatal intensive care & 7 & 4.43 \\
\hline Low birth weight & 7 & 4.43 \\
\hline $\begin{array}{l}\text { Placental abruption (ablatio } \\
\text { placentae) }\end{array}$ & - & - \\
\hline $\begin{array}{l}\text { PIH: pregnancy-induced hypertension; PPROM: preterm premature rupture of } \\
\text { the membranes }\end{array}$ \\
\hline
\end{tabular}

on this cut-off value; however no statistically significant difference was determined $(p=0.582)$ (Table 3). After calculating the UAPImean for each pregnant woman, the mean value of the entire group was calculated as 1.18. The entire group was divided into two subgroups according to the UAPImean value: $\leq 1.18$ or $\geq 1.19$. There was no statistically significant difference between the two subgroups in terms of poor pregnancy outcomes $(p=0.723)$, but the mean birth weights showed a significant difference ( $p=0.025)$, being lower in the subgroup with an UAPImean of $\geq 1.19$ than that of the subgroup with an UAPImean $\leq 1.18$ (Table 4 ).

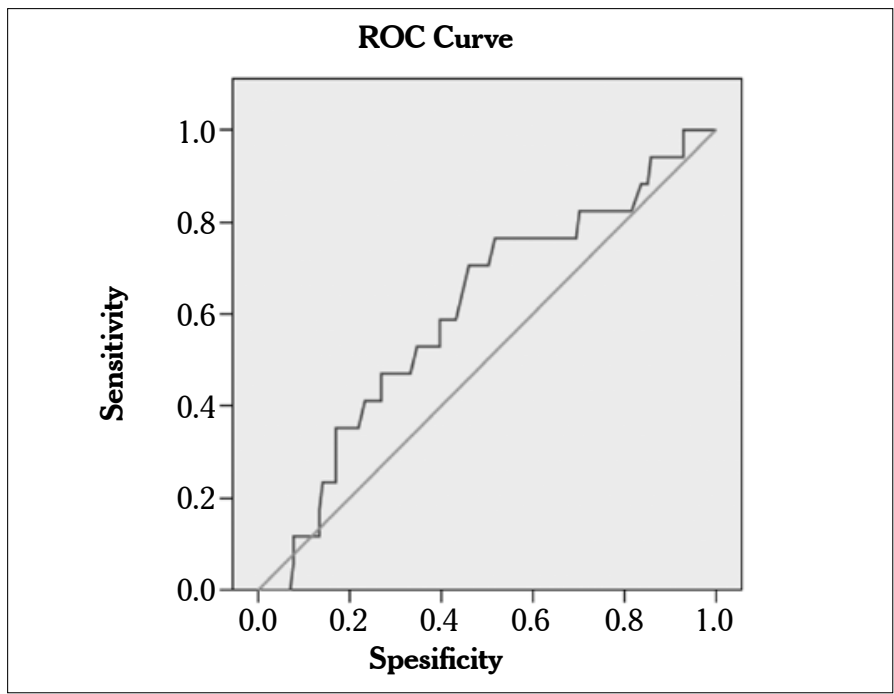

Figure 1. ROC curve for maternal serum PAPP-A level

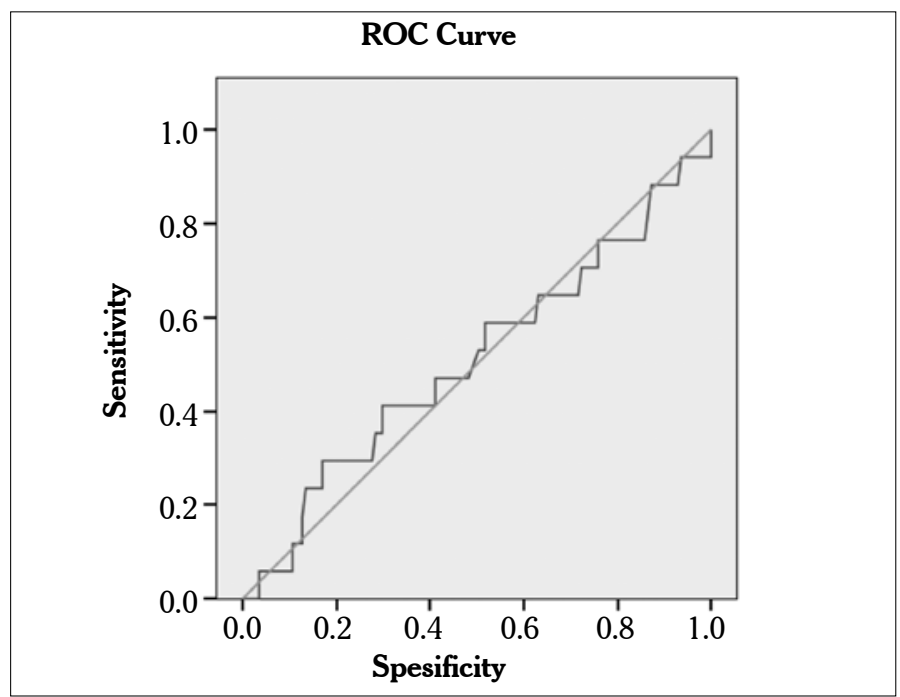

Figure 2. ROC curve for UAPImean

Table 3. Comparison of pregnancy outcomes between two subgroups formed according to the cut-off value of UAPImean determined by the ROC curve analysis

\begin{tabular}{|l|c|c|}
\hline Outcomes & $\begin{array}{c}\text { Number of patients } \\
(\mathbf{n}=17)\end{array}$ & $\begin{array}{c}\text { Percentage (\%) } \\
(\mathbf{n}=158)\end{array}$ \\
\hline$<1.08(\mathrm{n}=75)$ & $7(9.3 \%)$ & $68(90.7 \%)$ \\
\hline$\geq 1.08(\mathrm{n}=83)$ & $10(12 \%)$ & $73(88 \%)$ \\
\hline *Chi-square test: $\mathrm{p}=0.582$. & $\begin{array}{l}\text { UAPImean: arithmetic mean of the pulsatility indices of the right and left uterine } \\
\text { arteries; ROC curve: receiver operating characteristic curve }\end{array}$ \\
\hline
\end{tabular}

The mean RI (UARImean) value of both uterine arteries was calculated for each pregnant woman, and then an ROC curve was drawn (Figure 3). The sensitivity, specificity, PPV, and NPV values for the poor pregnancy outcomes were $58.8 \%, 34 \%, 36 \%$, and $47 \%$, respectively, when the cut-off value was taken as 0.582 (Standard Error, SE: 0.039) (95\% CI 0.646-0.798). After calculat- 
Table 4. Comparison of pregnancy outcomes and birth weight between two subgroups formed according to the UAPImean of the entire group

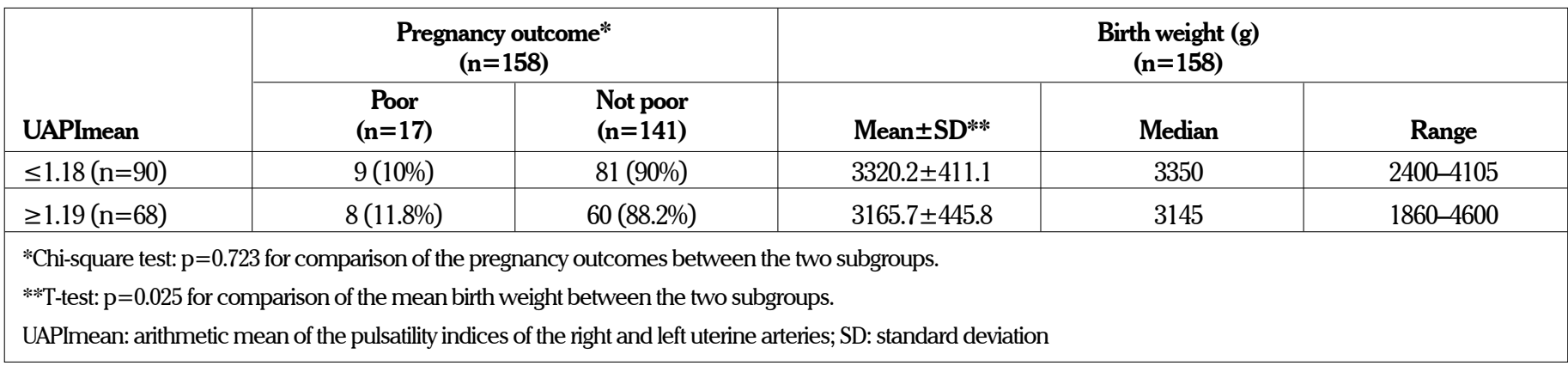

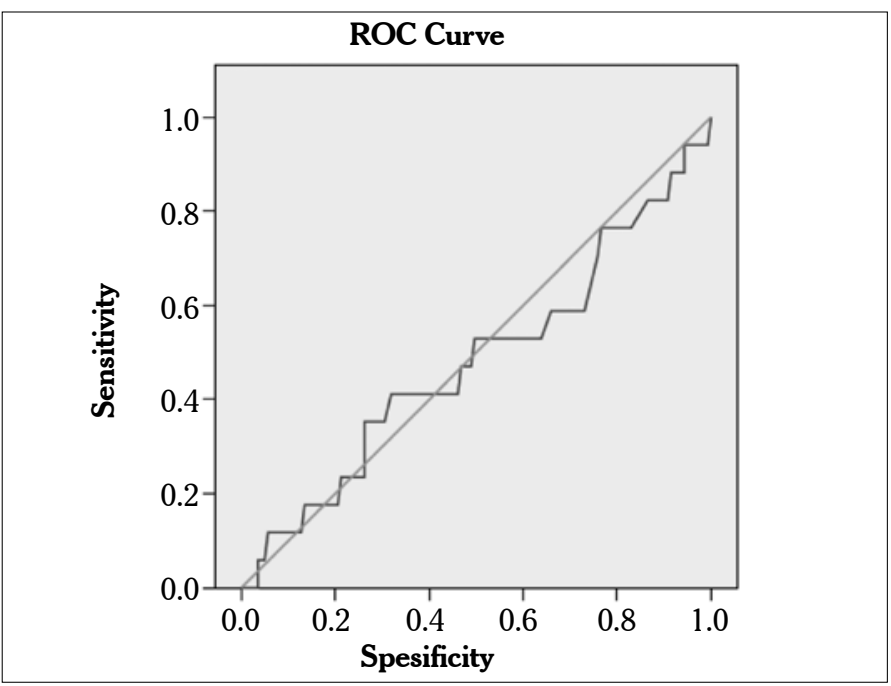

Figure 3. ROC curve for UARImean

ing the UARImean for each pregnant woman, the mean value of the entire group was calculated as 0.62 and the entire group was divided into two subgroups according to the UARImean values: $\geq 0.62$ or $<0.62$. No statistically significant difference was determined between the two subgroups in terms of pregnancy outcomes $(p=0.797)$, while the mean birth weight was significantly higher in the subgroup with UARImean $<0.62$ than that of the subgroup with an UARImean of $\geq 0.62(p=0.013)$ (Table 5). There was no significant difference between the women with unilateral uterine artery notch and the women with bilateral uterine artery notch in terms of pregnancy outcomes.

Receiver operating characteristic curves were drawn for $\mathrm{HC} / \mathrm{AC}$ ratio measured at the $20^{\text {th }}-24^{\text {th }}$ and $28^{\text {th }}-32^{\text {nd }}$ weeks of pregnancy (Figure 4, 5, respectively). Taking the cut-off value of $\mathrm{HC} / \mathrm{AC}$ ratio as 1.135 for the $20^{\text {th }}-24^{\text {th }}$ weeks of pregnancy (Standard Error, SE: 0.039) (95\% CI 0.646-0.798), the sensitivity, specificity, PPV, and NPV for poor pregnancy outcomes were 58.8\%, 49.6\%, 56\%, and $49 \%$, respectively. The cut-off value of $\mathrm{HC} / \mathrm{AC}$ ratio for the $28^{\text {th }}-32^{\text {nd }}$ weeks of pregnancy was taken as 1.075 (Standard Error, SE: 0.039) (95\% CI 0.646-0.798) with 52.9\% sensitivity, 41.1\% specificity, 59\% PPV, and 67\% NPV.

Pregnant women considered to be under the risk of early-onset IUGR (inconsistent FBMs subgroup), as specified in the Material and Methods section, were compared with the pregnant women with whom the estimated gestational age according to the

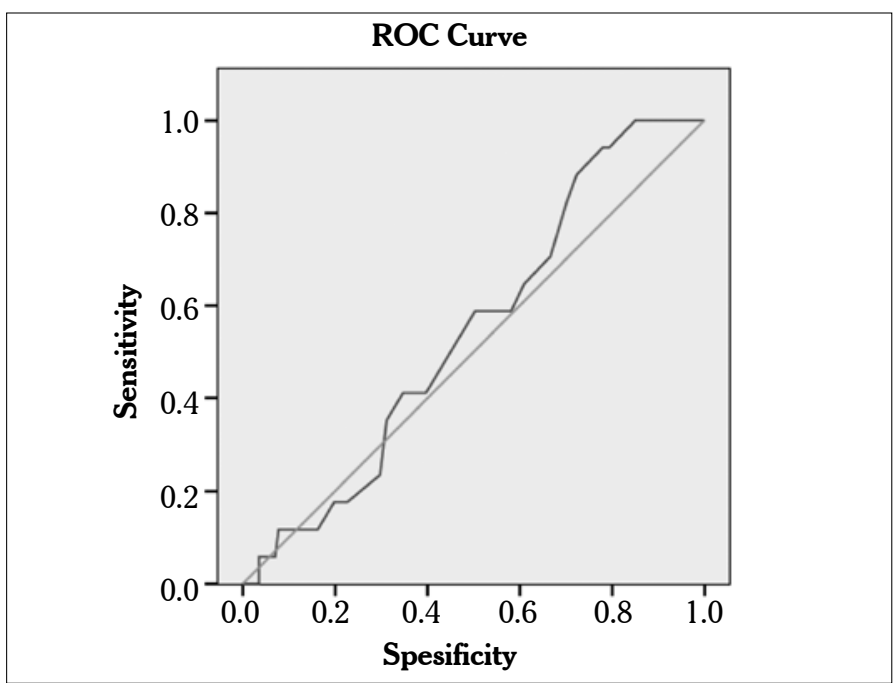

Figure 4. ROC curve for $\mathrm{HC} / \mathrm{AC}$ ratio measured at the $20^{\text {th }}-24^{\text {th }}$ weeks of pregnancy

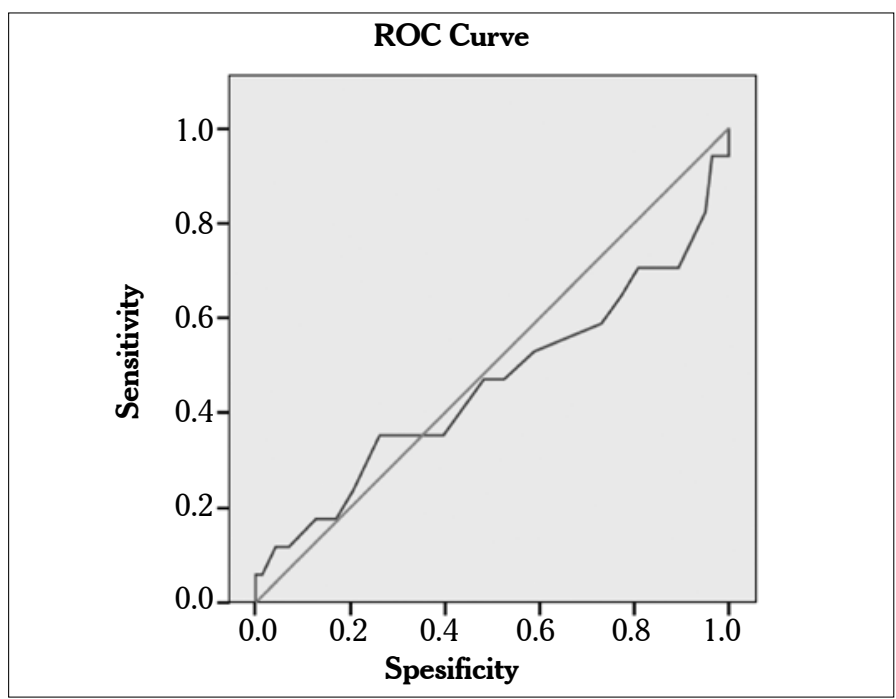

Figure 5 . ROC curve for $\mathrm{HC} / \mathrm{AC}$ ratio measured at the $28^{\text {th }}-32^{\text {nd }}$ weeks of pregnancy

fetal biometric measurement was consistent with the gestational age calculated according to the last menstrual period (consistent FBMs subgroup), in terms of the pregnancy outcomes and birth weight (Table 6). Statistically significant differences were 
determined between the two subgroups in terms of pregnancy outcomes $(p=0.045)$ and birth weight $(p=0.011)$.

\section{Discussion}

Impaired placentation is one of the most important causes of poor pregnancy outcomes for mother and/or the baby. Researches on the etiology of unpleasant outcomes of pregnancy, such as preeclampsia, IUGR, and preterm birth, highlight the importance of normal placental development. Markers that could indicate these changes prior to the onset of disorder will provide us a chance to take early preventive measures and even to prevent this in the future. For this reason, the world of perinatology has carried out many studies, particularly in recent years, on numerous placental biochemical markers, various Doppler ultrasound techniques and parameters, and various ultrasonographic methods to evaluate fetal and placental development in order to determine placental defects $(1,8,10,11)$. We aimed to determine the predictive value of the maternal serum PAPPA level of the first trimester, uterine artery Doppler velocimetry of the second trimester, and FBMs of the second and third trimester for poor pregnancy and poor neonatal outcomes which would probably occur due to placentation defect in pregnant women, and we found that the early prediction of unfavorable maternal and unfavorable neonatal outcomes of placental insufficiency might be possible using some test results, such as FBMs or an assessment of the HC/AC ratio, even though there is no method that can be used alone as a screening test.

Table 5. Comparison of pregnancy outcomes and birth weight between two subgroups formed according to the UARImean of the entire group

\begin{tabular}{|c|c|c|c|}
\hline \multirow[b]{2}{*}{ UARImean } & \multicolumn{2}{|c|}{$\begin{array}{l}\text { Pregnancy outcome* } \\
\quad(n=158)\end{array}$} & \multirow{2}{*}{$\begin{array}{l}\text { Birth weight }(\mathrm{g})^{* * *} \\
\quad(\mathrm{n}=158) \\
\text { Mean } \pm \mathrm{SD}^{* *}\end{array}$} \\
\hline & $\begin{array}{c}\text { Poor } \\
(n=17)\end{array}$ & $\begin{array}{l}\text { Not poor } \\
(n=141)\end{array}$ & \\
\hline$<0.62(\mathrm{n}=79)$ & $8(10.1 \%)$ & $71(89.1)$ & $3338.3 \pm 413.5$ \\
\hline$\geq 0.62(n=79)$ & $9(11.4 \%)$ & $70(\% 88.6)$ & $3169.1 \pm 435.8$ \\
\hline \multicolumn{4}{|c|}{$\begin{array}{l}\text { *Chi-square test: } p=0.797 \text { for comparison of the pregnancy outcomes between } \\
\text { the two subgroups. } \\
\text { **T-test: } p=0.013 \text { for comparison of the mean birth weight between the two } \\
\text { subgroups. } \\
\text { UARImean: arithmetic mean of the resistance indices of the right and left } \\
\text { uterine arteries }\end{array}$} \\
\hline
\end{tabular}

The association between low hCG $(<0.5$ MoM) and PAPP-A $(<0.4 \mathrm{MoM})$ levels, which are measured on the $10^{\text {th }}-14^{\text {th }}$ weeks of pregnancy, and the complications of pregnancy has been demonstrated previously $(15,16)$. In the present study as well, poor pregnancy outcomes could be predicted with $82.4 \%$ sensitivity and $29.8 \%$ specificity when the cut-off value was taken as $0.72 \mathrm{MoM}$ in the ROC curve drawn for PAPP-A, which was measured in the $11^{\text {th }}-14^{\text {th }}$ weeks of pregnancy.

Doppler ultrasonography of the uterine arteries is the other method used for the early prediction of pathological placentation and can be performed at various weeks of pregnancy. In the present study, a Doppler ultrasound of uterine arteries was performed on the $15^{\text {th }}-18^{\text {th }}$ weeks of pregnancy, the mean PI value of both sides was calculated (UAPImean), and then an ROC curve was drawn. We achieved a sensitivity of $58.8 \%$ and a specificity of $48.2 \%$ for poor pregnancy outcomes when the cutoff value was taken as 1.08. The average value of the entire group of pregnant women for UAPImean was found to be $1.18 \pm 0.40$, with no significant difference determined between pregnancy outcomes when the group was divided into two based on this value. However, a statistically significant difference was determined in terms of the mean birth weight $(p=0.025)$. The results, thus, indicate that increased uterine artery PI might cause a decrease in birth weight. Cooper et al. (17) conducted a study in 229 pregnant women and underlined the value of an increased mean uterine artery PI measured at the $22^{\text {nd }}$ week of pregnancy in predicting preterm birth, the small for gestational age (SGA), and a low birth weight, particularly in pregnant women with a PAPP-A value lower than 0.4 MoM. Pilalis et al. (18) evaluated 878 pregnant women on the $11^{\text {th }}-14^{\text {th }}$ weeks of pregnancy and emphasized that each of the Doppler ultrasound of uterine arteries and the PAPP-A value is an independent factor for predicting SGA and that the combination of both is more effective for prediction. The present study, showing an inverse relation between uterine artery PI and birth weight, differs from the other studies in that uterine artery PI has been evaluated within a different gestational age period of pregnancy. Nevertheless, it is necessary to underline that a normal PI does not exclude obstetric complications, as was demonstrated in almost all studies.

$\mathrm{RI}$ is another parameter assessed by Doppler ultrasound of the uterine arteries. In the present study, the mean RI of the uterine arteries (UARImean) was calculated for each pregnant woman and then an ROC curve was drawn. We were able to predict poor pregnancy outcome with $58.8 \%$ sensitivity and $34 \%$ specificity when the cut-off value was taken as 0.582 . The average

Table 6. Comparison of pregnancy outcomes and birth weight between two subgroups formed according to fetal biometric measurements

\begin{tabular}{|c|c|c|c|c|c|}
\hline \multirow[t]{2}{*}{ UAPImean } & \multicolumn{2}{|c|}{$\begin{array}{l}\text { Pregnancy outcome* } \\
\qquad(n=158)\end{array}$} & \multicolumn{3}{|c|}{$\begin{array}{c}\text { Birth weight }(\mathrm{g}) \\
\quad(\mathrm{n}=158)\end{array}$} \\
\hline & $\begin{array}{c}\text { Poor } \\
(n=17)\end{array}$ & $\begin{array}{l}\text { Not poor } \\
(n=141)\end{array}$ & Mean $\pm S D^{* * *}$ & Median & Range \\
\hline Inconsistent ( $\mathrm{n}=28)$ & $6(21.4 \%)$ & $22(78.6 \%)$ & $3075.7 \pm 341.1$ & 3110 & $2500-3740$ \\
\hline
\end{tabular}


value of UARImean was calculated for the whole group and the group was divided into two according to this value $(0.62 \pm 0.10)$. We failed to determine a significant difference between the groups in terms of obstetric complications; however, there was significant difference between the mean birth weights of the groups $(p=0.013)$. This result suggests that increased uterine artery RI, as well as increased PI, might cause a decrease in birth weight. The literature includes studies propounding that increased uterine artery RI and uterine notch can predict preeclampsia and SGA $(19,20)$. In these studies, which were performed in large population groups and usually in the $18^{\text {th }}-24^{\text {th }}$ weeks of pregnancy, the sensitivity reached $63-95 \%$ when RI was above the $95^{\text {th }}$ percentile or when the limit values of 0.56 0.58 were used for RI $(21,22)$. The RI found in the present study is close to those determined in earlier studies, although the cutoff value 0.582 was measured in a different gestational age period of pregnancy. The present study found no significant difference between the women with unilateral uterine artery notch and the women with bilateral uterine artery notch in terms of pregnancy outcomes.

Ultrasonographic biometry has always been an important tool in monitoring fetal development. In the present study, the pregnant women with whom estimated gestational age that was calculated based on ultrasonographic FBMs performed at the $20^{\text {th }}-24^{\text {th }}$ and $28^{\text {th }}-32^{\text {nd }}$ weeks of pregnancy was more than 1 week behind the gestational age calculated according to the last menstrual period and the pregnant women with an $\mathrm{HC}$ / $\mathrm{AC}$ ratio over 1.15 and 1.10 at the $20^{\text {th }}-24^{\text {th }}$ and $28^{\text {th }}-32^{\text {nd }}$ weeks of pregnancy, respectively, were considered to be under a risk of early onset fetal growth restriction. This high-risk group was compared with the other group of pregnant women and statistically significant differences were determined in terms of pregnancy outcomes $(\mathrm{p}=0.045)$ and mean birth weight $(p=0.011)$. In the literature, studies on this subject are not so many, excluding two separate studies conducted by Fox et al. $(12,13)$ suggesting an association between $\mathrm{aC} / \mathrm{AC}$ ratio $>90^{\text {th }}$ percentile and poor pregnancy outcomes and the study conducted by Colley et al. (23) determining a weak correlation between the $\mathrm{HC} / \mathrm{AC}$ ratio and the ponderal index. In addition to the literature information, the present study indicated that it is possible to obtain significant results in terms of pregnancy outcomes and birth weight in the light of precise FBMs and an assessment of the $\mathrm{HC} / \mathrm{AC}$ ratio $(23,24)$.

Our study has some limitations. First, power calculation was not performed, and we had a small sample size in terms of the subgroup with poor pregnancy outcomes. Second, we did not combine the results of the tests to analyze the predictive values of the combinations of current biochemical and ultrasonographic methods.

In conclusion, we aimed to determine the predictive value of maternal serum PAPP-A levels, uterine artery Doppler velocimetry, and FBMs for poor pregnancy and poor neonatal outcomes in pregnant women and found that serum PAPP-A levels and FBMs could be used for predicting pregnancy outcomes, while uterine artery Doppler velocimetry and FBMs could be used for predicting neonatal outcomes, specifically the birth weight. Therefore, an early prediction of unfavorable maternal and neo- natal outcomes of placental insufficiency might be possible using some test results, such as FBMs or by the assessment of the $\mathrm{HC} / \mathrm{AC}$ ratio, even though there is no method that can be used alone as a screening test. Therefore, different combinations of current biochemical and ultrasonographic methods may be necessary. It is clear that a screening test including certain combinations of biochemical and ultrasonographic markers with certain cut-off values, which will be created in multicenter studies with larger study populations, is needed in the future in order to predict obstetric complications earlier.

Ethics Committee Approval: Ethics committee approval was received for this study from the ethics committee of Dokuz Eylül University School of Medicine.

Informed Consent: Written informed consent was obtained from patients who participated in this study.

Peer-review: Externally peer-reviewed.

Conflict of Interest: No conflict of interest was declared by the authors.

Financial Disclosure: The authors declared that this study has received no financial support.

\section{References}

1. Smith GC, Shah I, Crossley JA, Aitken DA, Pell JP, Nelson SM, et al. Pregnancy-associated plasma protein A and alpha-fetoprotein and prediction of adverse perinatal outcome. Obstet Gynecol 2006; 107: 161-6. [Crossref]

2. Van den Elzen HJ, Cohen-Overbeek TE, Grobbee DE, Quartero RW, Wladimiroff JW. Early uterine artery Doppler velocimetry and the outcome of pregnancy in women aged 35 years and older. Ultrasound Obstet Gynecol 1995; 5: 328-33. [Crossref]

3. Martin AM, Bindra R, Curcio P, Cicero S, Nicolaides KH. Screening for pre-eclampsia and fetal growth restriction by uterine artery Doppler at 11-14 weeks of gestation. Ultrasound Obstet Gynecol 2001; 18: 583-6. [Crossref]

4. Dugoff L, Lynch AM, Cioffi-Ragan D, Hobbins JC, Schultz LK, Malone FD, et al. First trimester uterine artery Doppler abnormalities predict subsequent intrauterine growth restriction. Am J Obstet Gynecol 2005; 193: 1208-12. [Crossref]

5. Campbell S, Diaz-Recasens J, Griffin DR, Cohen-Overbeek TE, Pearce JM, Willson K, et al. New doppler technique for assessing uteroplacental blood flow. Lancet 1983; 1: 675-7.[Crossref]

6. Harrington K, Cooper D, Lees C, Hecher K, Campbell S. Doppler ultrasound of the uterine arteries: the importance of bilateral notching in the prediction of pre-eclampsia, placental abruption or delivery of a small-for-gestational-age baby. Ultrasound Obstet Gynecol 1996; 7: 182-8. [Crossref]

7. Steel SA, Pearce JM, McParland P, Chamberlain GV. Early Doppler ultrasound screening in prediction of hypertensive disorders of pregnancy. Lancet 1990; 335: 1548-51. [Crossref]

8. Huang T, Hoffman B, Meschino W, Kingdom J, Okun N. Prediction of adverse pregnancy outcomes by combinations of first and second trimester biochemistry markers used in the routine prenatal screening of Down syndrome. Prenat Diagn 2010; 30: 471-7. [Crossref]

9. Salvig JD, Kirkegaard I, Winding TN, Henriksen TB, Torring N, Uldbjerg N. Low PAPP-A in the first trimester is associated with reduced fetal growth rate prior to gestational week 20. Prenat Diagn 2010; 30: 503-8. [Crossref] 
10. Berry E, Aitken DA, Crossley JA, Macri JN, Connor JM. Screening for Down's syndrome: changes in marker levels and detection rates between first and second trimesters. Br J Obstet Gynaecol 1997; 104: 811-7. [Crossref]

11. Consuegra-Sanchez L, Fredericks S, Kaski JC. Pregnancy-associated plasma protein A: Has this biomarker crossed the boundary from research to clinical practice? Drug News Perspect 2009; 22: 341-8. [Crossref]

12. Fox NS, Shalom D, Chasen ST. Second-trimester fetal growth as a predictor of poor obstetric and neonatal outcome in patients with low first-trimester serum pregnancy-associated plasma proteinA and a euploid fetus. Ultrasound Obstet Gynecol 2009; 33: 34-8. [Crossref]

13. Fox NS, Huang M, Chasen ST. Second-trimester fetal growth and the risk of poor obstetric and neonatal outcomes. Ultrasound Obstet Gynecol 2008; 32: 61-5. [Crossref]

14. ACOG Committee on Obstetric Practice. Diagnosis and management of preeclampsia and eclampsia. Number 33, January 2002. American College of Obstetricians and Gynecologists. Int J Gynaecol Obstet 2002; 77: 67-75.

15. Morris RK, Cnossen JS, Langejans M, Robson SC, Kleijnen J, Ter Riet G, et al. Serum screening with Down's syndrome markers to predict pre-eclampsia and small for gestational age: systematic review and meta-analysis. BMC Pregnancy Childbirth 2008; 8: 33. [Crossref]

16. Gagnon A, Wilson RD, Audibert F, Allen VM, Blight C, Brock JA, et al. Obstetrical complications associated with abnormal maternal serum markers analytes. J Obstet Gynaecol Can 2008; 30: 918-49. [Crossref]

17. Cooper S, Johnson JA, Metcalfe A, Pollard J, Simrose R, Connors G, et al. The predictive value of 18 and 22 week uterine artery Doppler in patients with low first trimester maternal serum PAPP-A. Prenat Diagn 2009; 29: 245-8. [Crossref]

18. Pilalis A, Souka AP, Antsaklis P, Basayiannis K, Benardis P, Haidopoulos $\mathrm{D}$, et al. Screening for pre-eclampsia and small for gestational age fetuses at the 11-14 weeks scan by uterine artery Dopplers. Acta Obstet Gynecol Scand 2007; 86: 530-4. [Crossref]

19. Arduini D, Rizzo G. Normal values of Pulsatility Index from fetal vessels: a cross-sectional study on 1556 healthy fetuses. J Perinat Med 1990; 18: 165-72. [Crossref]

20. Dane B, Dane C, Kiray M, Cetin A, Koldas M, Erginbas M. Correlation between first-trimester maternal serum markers, second-trimester uterine artery doppler indices and pregnancy outcome. Gynecol Obstet Invest 2010; 70: 126-31. [Crossref]

21. Fonseca E, Yu CK, Singh M, Papageorghiou AT, Nicolaides KH. Relationship between second-trimester uterine artery Doppler and spontaneous early preterm delivery. Ultrasound Obstet Gynecol 2006; 27: 301-5. [Crossref]

22. Jacobson SL, Imhof R, Manning N, Mannion V, Little D, Rey E, et al. The value of Doppler assessment of the uteroplacental circulation in predicting preeclampsia or intrauterine growth retardation. Am J Obstet Gynecol 1990; 162: 110-4. [Crossref]

23. Colley NV, Tremble JM, Henson GL, Cole TJ. Head circumference/ abdominalcircumference ratio, ponderal index and fetal malnutrition. Should head circumference/abdominal circumference ratio be abandoned? Br J Obstet Gynaecol 1991; 98: 524-7. [Crossref]

24. Chambers SE, Hoskins PR, Haddad NG, Johnstone FD, McDicken WN, Muir BB. A comparison of fetal abdominal circumference measurements and Doppler ultrasound in the prediction of smallfor-dates babies and fetal compromise. Br J Obstet Gynaecol 1989; 96: 803-8. [Crossref] 